\title{
Graduate Students' Proficiency Strategy Attitutes on Autonomous Learning in Foreign Language Learning
}

\author{
Halil Küçükler ${ }^{1}$ \\ ${ }^{1}$ Balıkesir University, Turkey \\ Correspondence: Halil Küçükler, Balıkesir University, Turkey
}

Received: May 10, 2018 Accepted: June 19, 2018 Online Published: June 21, 2018

doi: 10.5539/elt.v11n7p142 URL: http://doi.org/10.5539/elt.v11n7p142

\begin{abstract}
The aim of the study is to investigate the strategy attitudes of graduate students' proficiency attitudes on autonomous learning in foreign language learning. This survey was conducted in Balikesir University in academic years of of 2014-2015. The survey analyses graduate (Master of Arts) students' foreign language learning styles and strategies to find out to what extent they are autonomous. Two kinds of questionnaires were administered. The first one was learner autonomy survey questionnaire developed by Zhang and Li (2004), which was administered to investigate how autonomous the participants were in learning English as a foreign language. The second one was the perceptual learning style preference questionnaire (PLSPQ) developed by Reid (1987). The two questionnaires were administered to 600 graduate students enrolled in the Institutions of Social Sciences and the Institution of Health at Balıkesir University in the academic years of 2014-2015. Only 504 graduate students responded the questionnaires. Then it was announced that there would be two types of English YDS preparation courses for the participants enrolled at Balıkesir University, Institute of M.A programs. 30 participants applied to join the courses. The participants are assigned to two groups, as instructed and non-instructed on voluntary bases. The results of data analysis showed that most of the participants preferred to learn English in class. But few students believed that they would be successful by self-study. The learners did not use strategies in high level but they used them in medium level.
\end{abstract}

Keywords: autonomous learning, proficiency, EFL

\section{Introduction}

\subsection{Autonomous Learning}

Autonomous learning is considered the pedestal of individuals' self-study, whereby, the individuals are largely responsible for their learning (Holec, 1981). The students must acquire knowledge, attitudes, and skills, majorly by interacting among themselves and information. The students can get information from various sources such as education facilities, media, and help from their tutors. Autonomous learning, therefore, enhances students to actively learn unlike the traditional mode of learning that promotes passive learning. In this case, the initiative to acquire information and gain knowledge is intrinsic (David, 1991). Due to this, the level of acquisition, retainance, and retrieval of information is high.

Moreover, autonomous learning enhances learning independence of students. Except in some isolated cases, every student has the ability to learn independently. Not only do students desire to exercise their independent learning abilities but the desire is also linked to the endeavor of being independent in life. According to Holec (1981) the tendency to ignore or underestimate students' independent learning ability leads to a gradual loss of student independence which can have a negative impact on the overall development of a student.

Autonomous learning promotes innovation. Essentially autonomous learning entails the process of students' innovative learning, and teachers' innovative teaching (Cao, 2000). This is to say that students find new ways of acquiring knowledge as well as teachers coming up with innovative ways of enhancing teaching. Central to autonomous learning is the need for the students to continually enhance their comprehensive ability and quality through innovation throughout the process of learning and teaching (Holec, 1981). The process of autonomous learning counters the passive traditional teaching procedure which is characterized by students unquestionably following the teachers' baton in learning marked by note taking, cramming the notes, and forgetting the notes once examined. 


\subsection{Importance of English}

The importance of language proficiency for improving educational performance through enhanced communication can never be over accentuated (Ludo \& John, 1992). It's been observed that students who portray difficulties in language proficiency may not function effectively, not only in the language related field but also in other academic fields. When language proficiency of an individual is high, it consequentially improves the academic performance of such an individual. Likewise, an individual with low language proficiency have demonstrated low academic performance. In a study conducted by Yushau (2015) focusing on the importance of English language proficiency in the performance of Mathematics, he concluded that individuals with high English proficiency concurrently demonstrated high performance in Mathematics. In a case where academic instructions are given using a language where a learner is less proficient, the learner face the dual challenge of having to learn in a foreign language while concomitantly learning content from another discipline though the second language (Ludo \& John, 1992). This can considerably slow down or at times totally impair the learning of the target subject where the foreign language is the medium of learning. Notably, English second language learners often have been considered less competent in academic related field in countries where English is the native language partly because of the challenges they encounter while using English as a medium of learning other academic disciplines (Yushau, 2015).

\section{Methodology}

\subsection{Participants}

This study was conducted with 30 graduate students enrolled at the institute of Social Sciences and Health for MA program at Balıkesir University. After the results of proficiency test which the subjects took at the beginning of November in the academic years of 2014-2015, two groups were selected for this research. The subjects were informed that there would be two types of program for the preparation of YDS exam. Detailed information was given about the two types of courses. The questionnaires were attached and mailed to all the students. The Institute has totally 1500 enrolled students at present. Only 504 students responded. 30 students applied to join the courses. 15 students wanted to take face to face course and the other 15 students wanted to study in the autonomous group.

\subsection{Instruments}

Strategy Inventory for Language Learning (SILL) (Oxford, 1990) was given to the research participants. The questionnaire covered fifty items. The participants were requested to arrange for their use of the strategy on a Likert scale. This scale consisted of 'never' or 'almost never'. The purpose of conducting the questionnaire was to help in identifying the language learning strategies as well as learning styles that are used by the graduate students in YDS examination. The learners' strategies, as well as learning styles were analysed under strategies such as Memory, Cognitive, Compensation, Meta-cognitive, Affective and Social.

\subsection{Data}

The Data obtained from the questionnaires, and the sample exam results were analysed quantitatively by using by the Statistical Package for Social Sciences (SSPS.17.0). Means, percentages, frequencies and standard deviations were calculated for the items.

\section{Results and Disscussion}

There are many strategies and learning styles that students apply in order to master the subject matter in autonomous learning. Some of the strategies include making notes and summaries during lessons, practicing English, using the library, attending seminars, and using audiovisual materials. The mostly used strategy among all is making notes and summary of the lessons that constitute a percentage of 26.4 that always, 20.6 often, 36.5 sometimes, 10.3 rarely and 6.3 never makes notes. Effective note making is very important in enabling the students to memorize the facts through writing (Piaget, 1977). Thus, in learning the English language, the learners perform better since they can remember and apply well through note making and summary. Furthermore, effective note making provides a record of an essential points for successful discussions.

The research shows that a percentage of 26 does not engage teachers or friends in conversations using the English language. However, $0.6 \%$ always, $6 \%$ often, 41.1 sometimes and 26.4 rarely talks to friends and students. The use of conversations not only develops social relationships but also enhances creativity and confidence among second language English speakers. Furthermore, other students record their voices as they speak to other people in English in order to recognize their verbal mistakes. However, $25 \%$ of the students never record their voices. Another strategy is the use of library sources to enhance linguistic skills. Only $15.1 \%$ always use the library, 0.8 often, 10.5 sometimes, 42.3 rarely and 31.3 never use the library. Libraries have a lot of reading materials that can improve the 
linguistic skills of an individual. However, most respondents in the study do not use it.

Others listen to audio visual presentations via television such as the BBC, watching movies as well as reading newspapers. The strategy is used by 13.5 percent who always watch movies, 19 . Often, 45.2 sometimes and 9.1 never. The strategy can be effective since movies are enjoyable and motivating. Furthermore, the language used on BBC programs is varied and authentic such that the vocabulary utilized is correct. Watching films enables students to grasp the natural flow of conversations and ways of expression. In addition, to that $7.3 \%$ of the total sample of respondents always attends seminars, 23.4 often, 30.8 sometimes, 34 rarely and 14.5 never attends. That implies that a higher percentage of the students value autonomous learning where they do not rely primarily on the teacher. The use of various strategies stated above enhances the oral communication skills in English. However, language learning relies majorly on practice (Collins, 2008). Autonomous learning strategies used by the students are individually chosen and used by students.

Graduate students apply various mechanisms to become independent learners of the English language. a higher percentage of graduate students revise lessons and books independently without the help of a tutor. In addition to that, others note their strengths and weaknesses and work on how to improve their linguistic skills. Although most of them are willing to learn English as a second language, very few students read extra materials in advance. Furthermore, some students motivate themselves by celebrating or buying new items when they succeed in English lessons. The study shows that all only 16.1 percent of the graduate students never reward themselves. To strengthen their mastery of subject matter in the English language, most graduate students use the internet to practice English except 0.8 percent.

The research tools also gave the students the chance to give their opinions on autonomous learning aspects. A percentage of 38.3 strongly disagreed the statement that learning can take place without a teacher. Only 15.1 strongly agreed, and 10.5 agreed. That is an implication that most students prefer the teacher-centred approach and do not believe they can learn from each other. To add on, the students also supported the fact that teachers must be responsible for the understanding of English language. In autonomous learning, the teacher can be present as a facilitator or guide but not the source of knowledge. Students in both the control and experimental group require a teacher to give guidelines. $50.8 \%$ and $46.6 \%$ strongly disagree and agree respectively with the suggestion that teachers should highlight errors and mistakes. That is justified by previous researchers that point out that the teacher offers guidance where he or she feels that the students goes wrong. That happened in both the control and experimental group.

In both the control and experimental group, the results of the YDS exam do not indicate any significant difference. The two groups used different techniques for instruction where one used the traditional while the other used the autonomous learning methods. That is an implication that all graduate students are motivated to learn the English language for future career use. In addition to that, the graduate students use English not only to pass their examinations but also for personal use such as communication, business and building social relationships. Besides that, English language skills in both oral and written enable the students understand the concepts in other courses effectively (Collins, 2008). Despite applying different programs and techniques, the students practiced the English language communication skills using strategies such as the audiovisuals, libraries, newspapers, movies and many more. Thus, the results were almost similar.

\section{References}

Cao, Y. (2000). Cultivation of Autonomous Learning Ability-Essential Requirement for College Students. Tokyo: Tokyo University Press Tokyo University of Foreign Studies.

Collins, S. R. (2008). Enhanced student learning through applied constructivist theory. Tranformative Dialogues: Teaching \& Learning Journal, 2(2), 1-9.

David, L. (1991). Definitions, Issues and Problems. Dublin: Authentik.

Ludo, V., \& John, H. A. L. (1992). The Construct of Language Proficiency: Applications of Psychological Models to Language Assessment (2nd ed.) Washington : John Benjamins Publishing.

Piaget, J. (1977). Thedevelopment of thought: Equilibration of cognitivestructures. New York: The Viking Press.

Reid, J. (1987). The learning style preferences of ESL students. TESOL Quarterly, 21, 87-111. https://doi.org/10.2307/3586356

Reid, J. (1995). Learning Styles in the ESL/EFL Classroom. Boston: Heinle \& Heinle.

Zhang, Z., \& Kenny, R. (2010). Learning in an online distance education course, Experiences of three international students, The International Review of Research in Open and Distributed Learning, 11(1), 17-36. 
https://doi.org/10.19173/irrodl.v11i1.775

\section{Copyrights}

Copyright for this article is retained by the author(s), with first publication rights granted to the journal.

This is an open-access article distributed under the terms and conditions of the Creative Commons Attribution license (http://creativecommons.org/licenses/by/4.0/). 